\title{
Controlled Pressure: The Solution for a High- Pressure Situation - Aetiology and Techniques for Control of Airway Haemorrhage
}

\author{
Suveer Singh ${ }^{a}$ Juergen Hetzel ${ }^{c}$ Pallav L. Shah ${ }^{a, b}$ \\ ${ }^{a}$ Chelsea and Westminster Hospital NHS Foundation Trust, and ${ }^{\mathrm{b}}$ The National Institute for Health Research Unit,

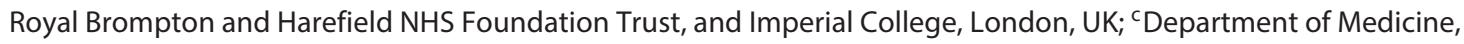 \\ University of Tübingen, Tübingen, Germany
}

Massive haemoptysis is a medical emergency with variably successful outcomes depending on the source, cause, and institution of effective control measures. Haemoptysis as a complication of fibrocavitatory lung disease, tuberculosis being the exemplar, is well described and variously innocuous or catastrophic. In the early 19th century, during his detailed correlations of clinical presentations with morbid anatomy, Laennec [1] suggested a pathological distinction between the common and often self-resolving "slight haemoptysis" and the universally catastrophic massive haemoptysis for which he developed the term pulmonary apoplexy. In these cases, he observed that the rupture of the aneurysmal pulmonary vessels (i.e., Rasmussen or intercostal artery) or rupture of often tortuous blood vessels with a weakened adventitia and media) traversing the tuberculous cavities were the main aetiological factor. It is suggested that budding capillaries in the granulation tissue increase the capillary bed supplied by the bronchial arteries, leading to increased load and hypertrophy [2]. Aspergillomas also lead to an extensive network of small vessels but usually from the pulmonary circulation. Several abnormal connections may exist in a single patient. In lung abscess, the pathogenesis of haemoptysis is not entirely clear but may be due to progression of local inflammatory processes causing necrosis of branches of the pulmonary artery [3].

\section{KARGER}

(C) 2017 S. Karger AG, Basel

E-Mail karger@karger.com

www.karger.com/res
Before the widespread use of effective chemotherapy, artificial pneumothoraces were created by clinicians treating tuberculosis in an attempt to collapse and "rest" the affected lung and heal cavitating disease [4]. This strategy of collapsing part of the lung was thought to reduce aerobic conditions and hinder mycobacterial progress. In 1882, the Italian physician Carlo Forlanini performed detailed theoretical and animal studies and developed specialised instruments enabling the injection of air into the pleural cavity. Artificial pneumothoraces created by the instillation of larger volumes ( $<3 \mathrm{~L}$ of nitrogen) by surgical incision and with X-ray guidance followed [5]. By 1912, it received recognition and became the primary therapy for pulmonary tuberculosis until the 1950s, when streptomycin and rifampicin became the frontline of clinical practice. Cessation of recurrent haemoptysis in pulmonary tuberculosis by repeated unilateral and bilateral pleural insufflation of air/oxygen or nitrogen was also established in the late 19th century [6].

The use of endobronchial techniques or devices for the control of haemoptysis is established. Bronchoscopy is performed to identify the source of bleeding, isolate the remaining lung, and create tamponade until there is control of the bleeding. Haemorrhage management involves suction above the point of bleeding, administration of cold saline, diluted adrenaline ( 1 in 100,000 to 1 in 200,000

Dr. Pallav L. Shah

Royal Brompton Hospital

Sydney Street

London SW3 6NP (UK)

E-Mail pallav.shah@imperial.ac.uk 
aliquots), tamponade of the source segment with the bronchoscope, or more effectively with endobronchial or para-axial balloons. Other options such as endobronchial tranexamic acid or surgical packing [7] have been proposed as further measures for controlling the bleeding. Methods such as turning the patient onto the side of the bleeding, double lumen endotracheal tubes, and the use of non-contact strategies such as endobronchial argon plasma coagulation [8] have also achieved success in isolated reports. The use of Watanabe spigots to control bleeding by isolating the source can be successful even in massive haemoptysis [9]. Use of antifibrinolytic agents, specifically tranexamic acid administered intravenously for haemoptysis in TB may shorten the duration of bleeding, but remission is unclear from limited studies [10]. However, the literature appears to confirm that some form of tamponade is the most effective way of controlling endobronchial bleeding.

A multidisciplinary approach is essential with rapid recourse to alternatives such as rigid bronchoscopy, interventional radiology, or surgery when initial bronchoscopic strategies fail. The role of interventional radiologydelivered bronchial artery embolization is very well established, withlow complicationswhengoodpre-embolization anatomy is definable [11]. Surgical resection must also be available if necessary and feasible, with good reported success rates of bleeding control in the aspergilloma literature [12].

Endobronchial inspiratory-only one-way valves have been developed for use in bronchoscopic lung volume reduction [13-17]. They have other uses such as in the control of persistent air leaks due to bronchopleural fistulae [18].

The report in Respiration by Lalla et al. [19] describes a 26-year-old HIV-positive patient with active tuberculo- sis requiring mechanical ventilation due to significant life-threatening haemoptysis in whom a bronchial arteriogram identified abnormal vessels to the left upper lobe cavity deemed to be the source of bleeding. The patient could not be liberated from mechanical ventilation due to recurrent haemoptysis. He was not fit for thoracotomy, and bronchial artery embolization was technically challenging without success. A conservative approach was adopted with the placement of endobronchial valves (EBVs) into the left upper lobe. There was radiographic lobar collapse, and importantly, collapse of the cavity. This was associated with cessation of bleeding. The patient was subsequently successfully extubated and made a good recovery. The authors had previously reported experience of this indication for EBVs in patents with haemoptysis from aspergillomata [20]. The successful application of this relatively straightforward endobronchial intervention raises questions about the mechanism of bleeding control and patient selection for this and other aspects of massive haemoptysis control.

EBVs will cause lobar or segmental collapse if no collateral ventilation exists [21]. Existence of collateral ventilation is less likely to be an issue in tuberculous disease than poor emphysema. The explanation for bleeding cessation is most easily explained if collapse occurred, as radiography suggested. In this situation, tamponade as a result of lobar collapse and in conjunction with hypoxic pulmonary vasoconstriction is the most likely explanation. The analogy with lobar collapse by artificial pneumothorax 200 years ago serves to remind us of the importance of historical developments in medical interventions, and modifications of previous techniques or physiological principles in contemporary emergency settings today.

\section{References}

1 Laennec E: The Anatomical Alterations in Vasculature around Pulmonary Cavities, $\mathrm{Pa}$ renchymal Caseation and Pleural Involvement of Phthisis. 1819.

2 Liebow AA, Hales MR, Lindskog GE: Enlargement of the bronchial arteries, and their anastomoses with the pulmonary arteries in bronchiectasis. Am J Pathol 1949;25:211-231.

3 Thoms NW, Wilson RF, Puro HE, et al: Lifethreatening hemoptysis in primary lung abscess. Ann Thorac Surg 1972;14:347-358.

4 Sakula A: Carlo Forlanini, inventor of artificial pneumothorax for treatment of pulmonary tuberculosis. Thorax 1983;38:326-332.

Controlled Pressure: The Solution for a High-Pressure Situation
5 Murphy JB: Surgery of the lungs. JAMA 1898; 31:151-165, 208-216, 281-297, 341-356.

6 Fernadez ZP: The value of artificial pneumothorax in the arrest and prevention of haemoptysis in pulmonary tuberculosis. BMJ 1918;2:55.

7 Valipour A, Kreuzer A, Koller H, Koessler W, Burghuber OC: Bronchoscopy-guided topical hemostatic tamponade therapy for the management of life-threatening hemoptysis. Chest 2005;127:2113-2188.

8 Morice RC, Ece T, Ece F, Keus L: Endobronchial argon plasma coagulation for treatment of hemoptysis and neoplastic airway obstruction. Chest 2001;119:781-787.
9 Dutau H, Palot A, Haas A, Decamps I, Durieux O: Endobronchial embolization with a silicone spigot as a temporary treatment for massive hemoptysis: a new bronchoscopic approach of the disease. Respiration 2006; 73 : 830-832.

10 Prutsky G, Domecq JP, Salazar CA, Accinelli $\mathrm{R}$ : Antifibrinolytic therapy to reduce haemoptysis from any cause. Cochrane Database Syst Rev 2016;11:CD008711.

11 Remy J, Arnaud A, Fardou H, et al: Treatment of hemoptysis by embolization of bronchial arteries. Radiology 1977;122:33-37.
Respiration 2017;93:398-400 DOI: $10.1159 / 000471927$ 
12 el Oakley R, Petrou M, Goldstraw P: Indications and outcome of surgery for pulmonary aspergilloma. Thorax 1997;52:813-815.

13 Slebos DJ, Shah PL, Herth FJ, Valipour A: Endobronchial valves for endoscopic lung volume reduction: best practice recommendations from expert panel on endoscopic lung volume reduction. Respiration 2017;93:138150.

14 Davey C, Zoumot Z, Jordan S, McNulty WH, Carr DH, Hind MD, Hansell DM, Rubens MB, Banya W, Polkey MI, Shah PL, Hopkinson NS: Bronchoscopic lung volume reduction with endobronchial valves for patients with heterogeneous emphysema and intact interlobar fissures (the BeLieVeR-HIFi study): a randomised controlled trial. Lancet 2015;386:1066-1073.
15 Shah PL, Herth FJ: Current status of bronchoscopic lung volume reduction with endobronchial valves. Thorax 2014;69:280-286.

16 Klooster K, Ten Hacken NH, Hartman JE, Kerstjens HA, van Rikxoort EM, Slebos DJ: Endobronchial valves for emphysema without interlobar collateral ventilation. N Engl J Med 2015;373:2325-2335.

17 Garner J, Kemp SV, Toma TP, Hansell DM, Polkey MI, Shah PL, Hopkinson NS: Survival after endobronchial valve placement for emphysema: a 10-year follow-up study. Am J Respir Crit Care Med 2016;194:519-521.
18 Dooms CA, De Leyn PR, Yserbyt J, Decaluwe $\mathrm{H}$, Ninane V: Endobronchial valves for persistent postoperative pulmonary air leak: accurate monitoring and functional implications. Respiration 2012;84:329-333.

19 Lalla U, Allwood BW, Sinha Roy S, Irusen EM, Koegelenberg CFN: Endobronchial valve used as salvage therapy in a mechanically ventilated patient with intractable life-threatening haemoptysis. Respiration 2017;93:436440.

20 Koegelenberg CFN, Bruwer JW, Bolliger CT: Endobronchial valves in the management of recurrent haemoptysis. Respiration 2014;87: 84-88.

21 Shah PL, Herth FJ: Dynamic expiratory airway collapse and evaluation of collateral ventilation with Chartis. Thorax 2014;69:290291 